\title{
Рукописный буддийский текст «Стослоговая мантра Ваджрасаттвы» на ойратском языке из Национального музея Тувы"
}

Байрта Б. Манджиева

Калмыцзий научный цзентр Российской академии наук, Российская Федерация,

\author{
Рита П. Сумба
}

Национальный музей им. Алдан-Маадыр Республики Тыва, Российская Федерация

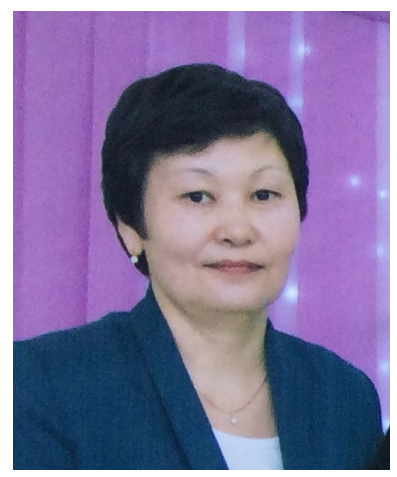

В статье вводится в научный оборот рукописный буддийский текст «Стослоговая мантра Ваджрасаттвы» в транслитерации и переводе на русский язык из собрания Национального музея Республики Тыва. Текст является частью ойратской рукописи, именуемой «Ekeyin zürken tarni orošiboi» ('Хридая-дхарани Матерей'). Примечателен тем, что представляет известную буддийскую стослоговую мантру Ваджрасаттвы, которая практикуется буддистами с древнейших времен до наших дней.

Ваджрасаттва - будда ваджраяны, символ чистоты Просветления (Бодхи) и Закона (Дхарма). Прочтение сакральной стослоговой мантры для буддистов имеет магическое значение: если прочесть ее сто восемь раз - очищает тяжелую карму человека; если произнести ее миллион раз - дарует просветление. Стослоговая мантра превыше всех других мантр, поэтому буддийские ламы говорят, что не существует практики более глубокой, чем «Стослоговая мантра Ваджрасаттвы».

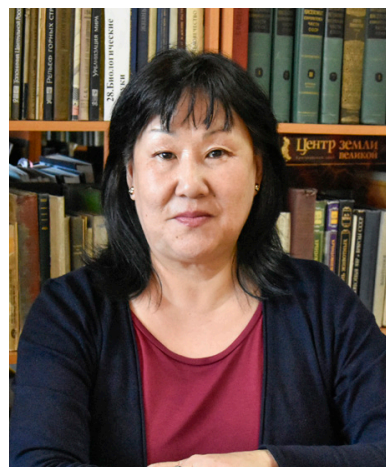

Ключевые слова: буддизм; рукописный текст; ойратский язык; стослоговая мантра; Ваджрасаттва; Национальный музей Республики Тыва; Тува

"Исследование проведено в рамках государственной субсидии - проект «Устное и письменное наследие монгольских народов России, Монголии и Китая: трансграничные традиции и взаимодействия» (регистрационный номер ААAА-А19-119011490036-1).

\section{Для цитирования:}

Манджиева Б. Б., Сумба Р. П. Рукописный буддийский текст «Стослоговая мантра Ваджрасаттвы» на ойратском языке из Национального музея Тувы [Электронный ресурс] // Новые исследования Tyвы. 2019, № 3. URL: https:// nit.tuva.asia/nit/article/view/874 (дата обращения: дд.мм.гг.). DOI: 10.25178/nit.2019.3.15

Манджсева Байрта Барбаевна - кандидат филологических наук, ведущий научный сотрудник отдела монгольской филологии Калмыцкого научного центра Российской академии наук. Адрес: 358000, Россия, г. Элиста, ул. И. К. Илишкина, д. 8. Тел.: +7 (961) 395-62-70. Эл. адрес: mbbairta@yandex.ru ORCID ID: 0000-0002-5644-3340

Сумба Рита Петровна - научный сотрудник отдела культуры, искусства и религии Национального музея им. Алдан-Маадыр Республики Тыва. Адрес: Адрес: 667000, Россия, г. Кызыл, ул. Титова, д. 30. Тел.: +7 (923) 384-32-91. Эл. адрес: risu1232001@ yahoo.de ORCID ID: 0000-0002-6296-2809

Mandzhieva Bayrta Barbayevna, Candidate of Philology, Leading Research Fellow, Department of Mongolian Philology, Kalmyk Scientific Center, Russian Academy of Sciences. Postal address: 8 Ilishkin St., 358000, Elista, Russian Federation. Tel .: +7 (961) 39562-70. E-mail address: mbbairta@yandex.ru

Sumba Rita Petrovna, Research Fellow, Department of Culture, Science and Religion, Aldan-Maadyr National Museum of the Republic of Tuva. Postal address: 30 Titov St., 667000 Kyzyl, Russian Federation. Tel.: +7 (923) 384-32-91. E-mail: risu1232001@ yahoo.de 


\title{
A Buddhist manuscript of 'The hundred-syllable mantra of Vajrasattva' in Oirat language from the National Museum of Tuva"
}

\author{
Bayrta B. Mandzhieva \\ Kalmyk Scientific Center of the Russian Academy of Sciences, Russian Federation, \\ Rita P. Sumba \\ Aldan-Maadyr National Museum of the Republic of Tuva, Russian Federation
}

\begin{abstract}
The article introduces (both in transliteration and translation into Russian) the handwritten Buddhist text 'The hundredsyllable mantra of Vajrasattva', preserved in the collection of the National Museum of the Republic of Tuva. The text is a part of an Oirat manuscript known as "Ekeyin zürken tarni orošiboi" ("Hridaya-dharani of Mothers'). It is remarkable in its representation of the famous Buddhist hundred-syllable mantra of Vajrasattva, which has been practiced by Buddhists from ancient times to the present day.

Vajrasattva is a Buddha of Vajrayana, a symbol of purity of Enlightenment (Bodhi) and the Law (Dharma). Reading the sacred hundred-syllable mantra for Buddhists has magical significance: if read one hundred and eight times, it cleans the heavy karma of a person; if pronounced a million times, it gives enlightenment. The hundred-syllable mantra is believed to be above all other mantras, therefore Buddhist lamas say that there is no deeper practice than the 'The hundred-syllable mantra of Vajrasattva'.
\end{abstract}

Keywords: Buddhism; manuscript; Oirat language; hundred-syllable mantra; Vajrasattva; National Museum of the Republic of Tuva; Tuva

\footnotetext{
" The study was carried out with support of a state subsidy - the project "Oral and Written Heritage of the Mongolian Peoples of Russia,
} Mongolia and China: Cross-Border Traditions and Interactions” (registration number AAAA-A19-119011490036-1).

For citaton:
Mandzhieva B. B. and Sumba R. P. A Buddhist manuscript of 'The hundred-syllable mantra of Vajrasattva' in Oirat
language from the National Museum of Tuva. The New Research of Tuva. 2019, № 3 [online] Available at: https://nit.tuva.
asia/nit/article/view/874 (access date ...). DOI: 10.25178/nit.2019.3.15

\section{Введение}

Буддизм, являясь самой древней из трех мировых религий, создал уникальную по масштабности и разнообразию каноническую литературу. Письменные буддийские памятники традиционно хранятся в ряде российских фондохранилищ музеев, архивов, научных учреждений, религиозных центров (Ринчинов, 2018; Музраева, 2019 и др.). Некоторые рукописи сохранились в архивных фондах Национального музея им. Алдан-Маадыр Республики Тыва, который является одним из главных культурнообразовательных центров Тувы. Достойное место среди собраний музея занимают рукописные тексты из коллекции по буддизму, в которой сохранились письменные источники на тибетском, монгольском и ойратском языках (Sazykin, 1996; Бичелдей, 2011). Коллекция монгольских и ойратских сочинений Национального музея Республики Тыва содержит 938 единиц хранения. Основная часть коллекции состоит из материалов, поступивших в музей из буддийских монастырей Тувы и частных коллекций (Сазыкин, 1992). А. Г. Сазыкин отмечает, что в фондах музея имеются также обширное собрание рукописей и ксилографов на тибетском языке (там же: 49-50).

Среди ойратской части собрания сохранился рукописный буддийский текст «Стослоговая мантра Ваджрасаттвы», который, по всей видимости, является частью ойратской рукописи, именуемой как «Ekeyin zürken tarni orošiboi» ('Хридая-дхарани Матерей’).

Текст примечателен тем, что представляет известную буддийскую стослоговую мантру Ваджрасаттвы, которая практикуется с древнейших времен до наших дней. Буддисты всего мира верят, что прочтение сакральной стослоговой мантры имеет магическое действие: очищает тяжелую карму человека, если прочесть ее сто восемь раз; дарует просветление, если произнести ее миллион раз. Благословен- 


\section{НОВЫЕ ИССЛЕДОВАНИЯ ТУВЫ}

www.nit.tuva.asia

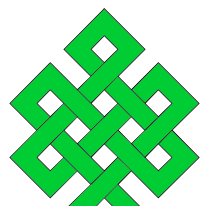

\section{THE NEW RESEARCH OF TUVA}

2019

Novye issledovaniia Tuvy

ный Ваджрасаттва воплощает божества ста семейств. Его называют «Ваджрасаттва - несравненное божество великой тайны». Стослоговая мантра превыше всех других мантр, поэтому буддийские ламы говорят, что не существует практики более глубокой, чем «Стослоговая мантра Ваджрасаттвы».

Цель статьи - введение в научный оборот текста ойратской рукописи «Стослоговая мантра Ваджра-
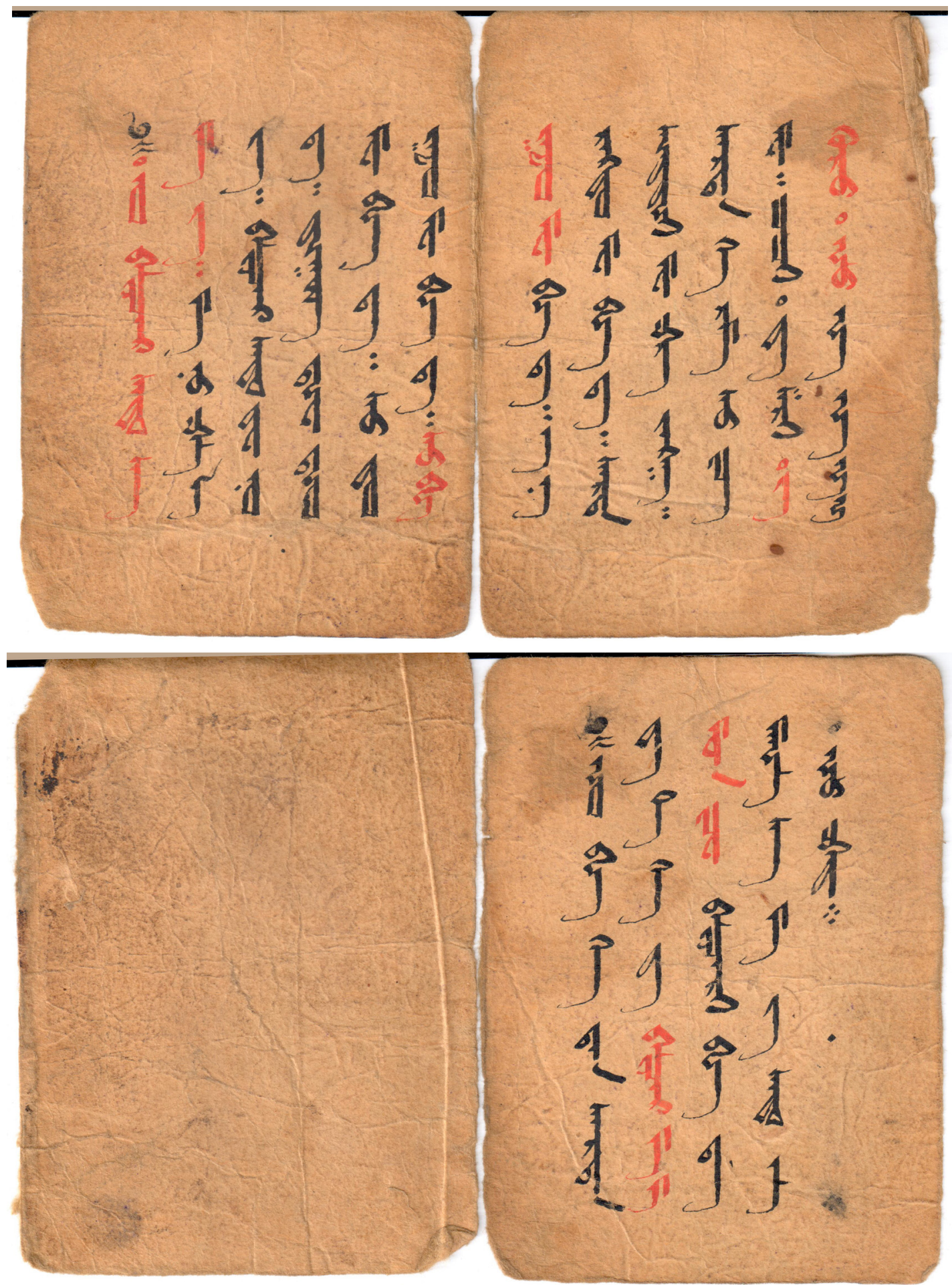

Фото 1-2. Фотокопия 1 и 2 листа ксилографа. Хранится в Национальном музее Тувы. Photo 1-2. Photocopy of xylograph sheets 1 and 2, courtesy of National Museum of Tuva. 


\section{Характеристика рукописи}

Рукопись состоит из двух листов малого формата, бумага плотная по структуре, листы имеют изгиб посередине (см. фото 1-2).

Второй лист в месте изгиба разорван, поэтому он состоит из двух частей. Несмотря на изношенность бумаги, текст хорошо сохранился, все слова четко видны.

Примечательно, что текст написан каллиграфическим почерком, черными и красными чернилами. В рукописи выделены красными чернилами начало текста, а именно слова «Om bādzar sadv sa-ma-ya» (Почитаю Ваджрасаттву, держателя самаи), далее выделено «su-do-šyo те» (Возрасти во мне), также выделяются слоги «јّạ guru hum»» (Сделай мой ум благим и добродетельным) и в конце выделены слоги «bādzar ma-ma munze» (Не покидай меня).

\section{О стослоговой мантре Ваджрасаттвы}

Стослоговая мантра Ваджрасаттвы - одна из наиболее популярных и распространенных в буддийском мире мантр. Считается, что мантра имеет чудотворную силу и, практикуя ее, человек может очиститься от негативных эмоций, плохих мыслей и слов, познать себя и духовно зарядиться. Эту особенную мантру с древнейших времен использовали буддийские монахи, желавшие духовного очищения.

Ваджрасаттва (санскр. vajra-sattva, тот, чья сущность ваджра) - будда ваджраяны, символ чистоты Просветления (Бодхи) и Закона (Дхарма) (Андросов, 2000: 90). Ваджрасаттва - букв. «алмазная душа» или «душа молнии», в тантрическом контексте данное значение указывает на обладателя нерушимости Закона (Дхарма) Будды, символизирует природу Будды, чистоту Просветления (Бодхи) и Закона (Дхарма). В буддийской мифологии Ваджрасаттва отождествляется с Ваджрадхарой, одним из главных будд ваджраяны, олицетворяющим единство всего сущего. Ваджрасаттва дарует сиддхи (санскр., букв. «совершенный» - человек, достигший совершенства, владеющий восемью сверхъестественными свойствами) проницательность, яснозоркость, см.: Герасимова, 1989: 7).

Изображается Ваджрасаттва в сидящей позе. Правой рукой он держит у сердца пятизубцовую ваджру осознанности и пустоты, в левой руке, у бедра, он держит колокольчик видимости и пустоты, символизирующие искусные средства и мудрость. Ноги его скрещены в позе ваджры. На нем тринадцать элементов облачения: пять шелковых одежд и восемь украшений. Пять шелковых одежд - это: 1) головная повязка; 2) одеяние, покрывающее верхнюю часть тела; 3) длинный шарф; 4) пояс; 5) одеяние, покрывающее нижнюю часть тела. Восемь украшений - это: 1) диадема; 2) серьги; 3) короткое ожерелье; 4) браслет на каждом предплечье; 5) два длинных ожерелья - одно длиннее, другое короче; 6) браслет на каждом запястье; 7) кольцо на каждой руке; 8) ножной браслет на каждой ноге.

В мифологии Ваджрасаттву отождествляют с одним из главных будд ваджраяны Ваджрадхарой (vadjra-dxara, или Держатель ваджры).

\section{Правила очищения проступков четырьмя силами}

Главным препятствием для всякого неординарного переживания и для достижений на глубоком пути Дхармы являются негативные действия, омрачения и привычные модели поведения (т. е. модели поведения, сложившиеся вследствие прошлых действий) (Патрул, 2007: 363). Для устранения не благих действий, проступков существуют многочисленные приемы очищения, наилучшим из которых является медитация и чтение мантры Ваджрасаттвы.

«Хотя стараемся не запятнаться грехопадениями, но, если по неосмотрительности, из-за обилия омрачений и т. п. допускаем проступки, то нельзя оставлять их без внимания, необходимо прилагать усилия к средствам исправления, заповеданным сострадательным Учителем» (Чже Цонкапа, 2007: 319). Исправление проступков должно производиться посредством четырех сил - сила опоры, сила раскаяния в содеянном, сила решимости и, в качестве противоядия, сила действия.

Чже Цонкапа (1357-1419) - основоположник наиболее влиятельной из школ тибетского буддизма Гелуг, является автором знаменитого труда «Большое руководство к этапам Пробуждения» (Ламримченмо), в котором он изложил важнейшие идеи индо-тибетского буддизма в форме систематического руководства, описывающего весь путь духовного развития вплоть до достижения Пробуждения. В данном труде приводятся правила очищения проступков четырьмя силами. 
Первая из этих сил - многократное покаяние в неблагих деяниях, совершенных с безначального времени. Чтобы она зародилась, нужно созерцать возможность порождения созревших и других из трех неблагих деяний.

Вторая сила - сила раскаяния в содеянном, которая проистекает из чувств угрызения совести вследствие тех неблагих действий, совершенных в прошлом. Во время практики раскаяния необходимо думать о шести вещах:

«1) время - раскаиваться во всех неблагих действиях, совершенных в течение этой жизни - в определенный месяц, день, момент и т. п.;

2) мотивация - сожалеть о действиях, совершенных под воздействием желания, отвращения и заблуждения;

3) накопление - раскаиваться во всей накопленной негативности в плане тела, речи и сознания;

4) характер действия - раскаиваться как в действиях, которые сами по себе являются неблагими (такие как десять неблагих действий, пять действий с немедленным воздействием и т. д.), так в особых поступках, таких как нарушение своих обетов и т. п.;

5) объект действия - раскаиваться во всех ложных действиях, направленных как на сансару, так и на нирвану;

6) карма - раскаиваться во всех вредоносных действиях и срывах, которые привели к короткой жизни, множеству болезней, бедности, страху перед врагами и бесконечному блужданию в низших сферах» (Патрул, 2007: 516).

Третья сила - сила решимости. Сила решимости состоит в том, чтобы помнить совершенные ошибки и принять решение впредь никогда не повторять их, даже ради спасения собственной жизни, которой мы так дорожим.

Четвертая сила - сила действия в качестве противоядия. Четвертая сила предполагает совершение как можно большего числа благих действий в качестве противоядия против наших прошлых неблагих действий (Чже Цонкапа, 2007: 319-322).

Медитируя о Ваджрасаттве и читая мантру, необходимо помнить о характерном значении каждого элемента в контексте четырех сил, используемых как противоядие (Powers, 2007: 306).

Прочтение стослоговой мантры без перерыва сто восемь раз очищает неблагие действия и омрачения, а также все нарушения и все пробелы в обетах и в заветах. Стослоговая мантра - «это квинтэссенция сознания всех Сугат ${ }^{1}$. Она очищает все нарушения, все падения, все обусловленные омрачения. Она - высшее покаяние. Прочитав ее без перерыва сто восемь раз, исправишь все нарушения и промахи и спасешься от падения в три низшие сферы <..> . Сто тысяч чтений стослоговой мантры полностью очистят все ваши падения и срывы» (Патрул, 2007: 379).

Многие негативные эмоции, такие как, гнев, зависть, ревность создают большое количество кармических отпечатков в нашем сознании. Если человек устраняет эти отрицательные эмоции вместе с их источником (неведение, себялюбие), то его сознание полностью освобождается от всех умственных заболеваний. Тибетский буддийский наставник Геше Джампа Тинлей подобное состояние ума называет освобождением, нирваной (Тинлей, Электр. ресурс).

\section{Транслитерация текста ${ }^{2}$}

[1] Om bādzar sadv sa-ma-ya: ma-nu pā-la-ya:

bādzar sadv te-no-pa:

dištta dhe-dho me-bha-va:

su-do-šyo me-bha-va:

su-bha-šyo me-bha-va:

a-na raqdo me-bha-va:

sarva siddhi me-pra-yakša:

${ }^{1}$ Сугата - (санскр. Sugata, тиб. bde bar gshegs pa) - эпитет Будды, Просветлённого, как существующего ради добра, блага, счастья.

${ }^{2}$ В транслитерации текста использованы следующие условные знаки: квадратные скобки [ ] заключают в себе вставки, обозначающие начало текста на листе; двойное двоеточие обозначает конец произведения. 
sarva ka-rma su-ǰa-me:

y̌ji-dam šri-ǰam guru hum

ha ha ha ha [2] ho bha-ga-van

sarva da-ta-ga-da

bādzar ma-ma munze

bādzar bha-va mahā

sa-ma-ya sadv-ā

hum pad::

\section{Перевод на русский язык \\ СТОСЛОГОВАЯ МАНТРА}

Молитва, призывающая потоки ума Будд

Почитаю

Ваджрасаттву, держателя самой [Бодхисаттвы]:

О Ваджрасаттва, защити самаи.

Да пребудь во мне непоколебимо.

Ниспошли мне полное удовлетворение.

Возрасти во мне.

Возлюби меня.

Даруй мне все сиддхи.

Яви мне все кармы.

Сделай мой ум благим и добродетельным.

(Сердечный слог Ваджрасаттвы)

(Четыре ступени достижения)

(Восклицание радости при таком свершении)

О Благословенный, воплощающий всех ваджрных Татхагат,

Не покидай меня.

Сделай меня единым с тобой.

(Единение не в двойственности).

Благодаря мощи молитвы, исполненной четырех сил во всей полноте,

Ваджрасаттва с Супругой тают в свете и растворяются во мне.

Мое тело в одиночной форме Ваджрасаттвы - кристально чистое,

Я представляю свет, излучающийся из шестислоговой мантры

в моем сердце.

Все окружение и все существа становятся Ваджрасаттвами

Пяти Семейств и растворяются во мне.

Я таю в свете. Свет растворяется в [слоге] ОМ,

И далее постепенно [все растворяется]

по часовой стрелке до [слога] ХУМ.

Покойся в состоянии без умопостроений.

Потом осваивай явленное и пустоту:

божество, мантру и самадхи (Зангдок, 2014: 50-53).

\section{Заключение}

Рассмотренный нами текст, являясь частью ойратской рукописи «Ekeyin zürken tarni orošiboi» ('Хридая-дхарани Матерей’), свидетельствует о широком распространении тибето-монгольской буддийской традиции в Туве. В этой связи изучение и введение в научный оборот ойратских текстов, хранящихся в Национальном музее им. Алдан-Маадыр, является актуальным для изучения как истории буддизма, так и буддийских связей регионов, и в перспективе позволит проводить сравнительно-сопоставительный анализ письменных источников, сохранившихся в Калмыкии и Туве. 


\section{СПИСОК ЛИТЕРАТУРЫ}

Андросов, В. П. (2000) Словарь индо-тибетского и российского буддизма: главные имена, основные термины и доктриальные понятия. М. : Вестком. 200 с.

Бичелдей, У. П. (2011) Собрание буддийских рукописей и ксилографов в фондах Национального музея Республики Тыва как памятники духовной культуры тувинского народа // Память мира: историкодокументальное наследие буддизма. Мат-лы Межд. науч.-практ. конф. / отв. ред. В. В. Минаев. М. : РГГУ. 359 с. С. $228-233$.

Герасимова, К. М. (1989) Традиционные верования тибетцев в культовой системе ламаизма. Новосибирск: Наука. 320 с.

Зангдок, П. (2014) Тексты практик традиции Лонгчен Ньингтик. М. : Центр Дрикунг Кагью Ратна Шри. 165 с.

Музраева, Д. Н. (2019) Из истории комплектования и описания Фонда-8 Научного архива КалмНЦ РАН (по описи В. О. Поляева) // Oriental Studies. 2019. Вып. 3. С. 450-459. DOI: 10.22162/2619-0990-201943-3-450-459

Патрул, Р. (2007) Слова моего несравненного Учителя / с предисловием Далай-ламы и Дилго Кхенце Ринпоче. СПб. : Издание А. Терентьева. 607 с.

Ринчинов, О. С. (2018) Библиографическая база данных «Тибетоязычные источники по традиционной медицине» // Научные и технические библиотеки. Вып. 4. С. 72-83. https://doi.org/10.33186/10273689-2018-4-72-83

Сазыкин, А. Г. (1992) Собрание монгольских рукописей и ксилографов из фондов Тувинского республиканского краеведческого музея им. 60 богатырей (Кызыл) // Тюркские и монгольские письменные памятники. Текстологические и культуроведческие аспекты исследования: сборник статей / отв. ред. С. Г. Кляшторный и Ю. А. Петросян. М. : Наука. Восточная литература. 162 с. С. 45-58.

Тинлей, Д. Основы буддийской философии. Лекции прочитаны в Республиканском институте повышения квалификации работников образования Республики Калмыкия / пер. М. Малыгиной [Электронный ресурс] // Библиотека буддийских текстов. www.geshe.ru. URL: http://geshe.ru/books/GesheDjampaTinley/Geshe_Dzhampa_Tinlei___Osnovy_buddiiskoi_filosofii.pdf (дата обращения: 28.02.2019).

Чже, Цонкапа (2007) Большое руководство к этапам пути Пробуждения : в 2-х т. СПб.: Издание А. Терентьева. Т. 1.786 с.

Sazykin, A. (1996) The Collection of Mongolian Manuscripts and Xylographs in the Ethnological Museum of the Republic of Tuva in Kyzyl // Manuscripta Orientalia. Vol. 2, no. 2. P. 44-49.

Powers, J. (2007) Introduction to Tibetan Buddism. Ithaca, NY, USA. 591 p.

Дата поступления: 05.05.2019 2.

\section{REFERENCES}

Androsov, V. P. (2000) Slovar' indo-tibetskogo i rossiiskogo buddizma: glavnye imena, osnovnye terminy $i$ doktrinal'nye poniatiia [A dictionary of Indo-Tibetan and Russian Buddhism: major names, basic terms and doctrinal concepts]. Moscow. 200 p. (In Russ.).

Bicheldey, U. P. (2011) Sobranie buddiyskikh rukopisey i ksilografov v fondakh Natsional'nogo muzeya Respubliki Tyva kak pamyatniki dukhovnoy kul'tury tuvinskogo naroda [A collection of Buddhist manuscripts and woodcuts in the funds of the National Museum of the Republic of Tuva as monuments of spiritual culture of the Tuvan people]. In: Pamyat' mira: istoriko-dokumental'noe nasledie buddizma [Memory of the world: the historical and documentary heritage of Buddhism]: Proceedings of an international conference / ed. by V. V. Minaev. Moscow, Russian State University for the Humanities. 359 p. Pp. 228-233. (In Russ.).

Gerasimova, K. M. (1989) Traditsionnye verovaniia tibettsev $v$ kul'tovoi sisteme lamaizma [Traditional Tibetan beliefs in the cult system of Lamaism]. Novosibirsk, Nauka. 320 p. (In Russ.).

Zangdok, P. (2014) Teksty praktik traditsii Longchen N'ingtik [Texts of the Longchen Nyingtik Practices]. Moscow, Centr Drikung Kag'ju Ratna Shri. 165 p. (In Russ.).

Muzraeva, D. N. (2019) Iz istorii komplektovaniya i opisaniya Fonda-8 Nauchnogo arhiva KalmNC RAN (po opisi V. O. Polyaeva) [Fond 8 of the Scientific Archive of the Kalmyk Scientific Center (RAS): Excerpts from 
the History of Its Formation and Description (an Insight into V. O. Polyaev's Inventory List)]. Oriental Studies, issue 3, pp. 450-459. DOI: 10.22162/2619-0990-2019-43-3-450-459. (In Russ.).

Patrul, R. (2007) Slova moego nesravnennogo Uchitelia / s predisloviem Dalai-lamy i Dilgo Kkhentse Rinpoche [The words of my incomparable Master / with the foreword of the Dalai Lama and Dilgo Khyentse Rinpoche]. St. Petersburg. 607 p. (In Russ.).

Rinchinov, O. S. (2018) Bibliographic Database "Sources in traditional medicine in Tibet languages". Scientific and Technical Libraries, issue 4, pp. 72-83. DOI: 10.33186/1027-3689-2018-4-72-83 (In Russ.).

Tinlei, D. Osnovy buddiiskoi filosofii. Lektsii prochitany v Respublikanskom institute povysheniia kvalifikatsii rabotnikov obrazovaniia Respubliki Kalmykiia [Fundamentals of Buddhist philosophy. Lectures given at the Republican Institute for Advanced Training of Education Workers of the Republic of Kalmykia] / transl. by M. Malygina. Biblioteka buddiiskikh tekstov. www.geshe.ru [online] Available at: http://geshe.ru/books/ GesheDjampaTinley/Geshe Dzhampa Tinlei-Osnovy buddiiskoi filosofii.pdf (access date: 28.02.2019). (In Russ.).

Chzhe, Zonkapa (2007) Bol'shoe rukovodstvo k etapam puti Probuzhdeniia [The great guide to the stages of the path of Awakening] : in 2 vols. St. Petersburg, A. Terent'ev Publ. Vol. 1. 786 p. (In Russ.).

Sazykin, A. G. (1992) Sobranie mongol'skih rukopisei i ksilografov iz fondov Tuvinskogo respublikanskogo kraevedcheskogo muzeya im. 60 bogatyrei (Kyzyl) [The collection of Mongolian manuscripts and xylographs in Aldan-Maadyr National Museum in Kyzyl]. In: Tyurkskie i mongol'skie pis'mennye pamyatniki. Tekstologicheskie $i$ kul'turovedcheskie aspekty issledovaniya [Turkic and Mongolian monuments of writing: Textual and cultural aspects of research]. Ed. by S. G. Kliashtornyi and Iu. A. Petrosian. Moscow, Nauka, Vost. Lit. Publ. 162 p. P. 45-58. (In Russ.).

Sazykin, A. (1996) The Collection of Mongolian Manuscripts and Xylographs in the Ethnological Museum of the Republic of Tuva in Kyzyl. Manuscripta Orientalia, vol. 2, no. 2, pp. 44-49.

Powers, J. (2007) Introduction to Tibetan Buddism. Ithaca, NY, USA. 591 p.

Submission date: 05.05.2019. 